\title{
Transesterification of Waste Cooking Oil using Calcium Loaded on Deoiled Spent Bleaching Clay as A Solid Base Catalyst
}

\author{
Rehan Zainol Abidin ${ }^{1}$, Gaanty Pragas Maniam ${ }^{1,2^{*}}$, Mohd Hasbi Ab. Rahim ${ }^{1}$ \\ ${ }^{1}$ Faculty of Industrial Sciences and Technology, Universiti Malaysia Pahang, \\ Lebuhraya Tun Razak, 26300 Gambang, Kuantan, Pahang, Malaysia \\ ${ }^{2}$ Central Laboratory, Universiti Malaysia Pahang, \\ Lebuhraya Tun Razak, 26300 Gambang, Kuantan, Pahang, Malaysia
}

Received: 21 ${ }^{\text {st }}$ January 2016; Revised: $3^{\text {rd }}$ March 2016; Accepted: $6^{\text {th }}$ March 2016

\begin{abstract}
Waste cooking oil has a high potential as a raw material in biodiesel production due to its abundant availability and cheapest among other feedstock. Hence transesterification reaction is carried out using waste cooking oil in this research. The objective of this study is to synthesize and characterize the catalyst. On the other hand, deoiled spent bleaching clay impregnated with $40 \% \mathrm{CaO}$ utilized as a catalyst. Optimization was carried out on methanol to oil molar ratio (6:1-24:1), catalyst loading (3-10 wt.\%) and reaction duration $(2-10 \mathrm{~h})$. The catalyst of deoiled spent bleaching clay doped with $40 \% \mathrm{CaO}$ was prepared by wet impregnation method and calcined at $500{ }^{\circ} \mathrm{C}$ for 4 hours. The catalyst shows high activity under optimum condition of 5 hours of reaction time, $12: 1$ of methanol to oil molar ratio with $7 \mathrm{wt} . \%$ of catalyst. The transesterification yields $84.7 \%$ methyl ester. Therefore, this catalyst has potential to be used in the transesterification of waste cooking oil in producing biodiesel due to its high activity. Copyright (C) 2016 BCREC GROUP. All rights reserved
\end{abstract}

Keywords: Biodiesel; Waste cooking oil; Spent bleaching clay; Calcium oxide; Transesterification

How to Cite: Abidin, R.Z., Maniam, G.P., Rahim, M.H.A. (2016). Transesterification of Waste Cooking Oil using Calcium Loaded on Deoiled Spent Bleaching Clay as A Solid Base Catalyst. Bulletin of Chemical Reaction Engineering \& Catalysis, 11 (2): 176-181 (doi:10.9767/bcrec.11.2.548.176-181)

Permalink/DOI: http://dx.doi.org/10.9767/bcrec.11.2.548.176-181

\section{Introduction}

Biodiesel has been more attractive recent years because of its environmental benign and the fact that it is made from renewable resources [1,2]. Increasing cost of petroleum and other environmental problems made researchers found an alternative to fossil fuel which is

* Corresponding Author.

E-mail: gaanty@ump.edu.my (G.P. Maniam), Telp:+609-5492305, Fax: +609-5492766 biodiesel which are derived from vegetable oils or animal fats with ethanol or methanol $[3,4]$. Biodiesel does not need any engine modification (or little) and can be used in compressionignition (diesel) engine due to its excellent properties as diesel engine fuel [5].

There is an alternative process to homogeneous catalysed transesterification for biodiesel production which is heterogeneous catalysed transesterification [6]. They have many advantages such as less wastewater generation and their ability to recycle or reuse [7, 8]. Hence, 
further development of heterogeneous catalysts must focus on enhancing, not only catalytic performance but also the reusability [9]. A large variety of heterogeneous catalysts have been investigated [10]. Among them, $\mathrm{CaO}$ has been received much interest since relatively cheap, it's mild reaction condition and less impact on environment [11]. Calcium oxide $(\mathrm{CaO})$ has been reported recently as an active heterogeneous base catalyst for transesterification reaction. This is due to ease of handling, low solubility and its high basicity $[12,13]$. The usage of $\mathrm{CaO}$ can be categorized into the group of neat $\mathrm{CaO}$, doped $\mathrm{CaO}$, waste $\mathrm{CaO}$, mixed $\mathrm{CaO}$ and supported $\mathrm{CaO}[14,15]$. Until now, there has been limited work to prepare alkali metal based catalyst in macroscopic to catalyse the transesterification reaction for biodiesel production [16]. We need high surface area catalyst to work with transesterification reaction so that can increase the rate of reaction. Calcium oxide doped onto the deoiled spent bleaching clay has been chosen to be the catalyst as it is comparatively cheap and giving high methyl ester conversion compared to other the catalyst. Furthermore, calcium oxide has lower leaching effect in comparison with potassium oxide.

In this work, the transesterification of waste cooking oil with methanol has been investigated using deoiled-SBC loaded with $40 \% \mathrm{CaO}$ as a catalyst including studied the structural and catalytic properties of the catalyst by several methods.

\section{Materials and Methods}

\subsection{Material}

The waste cooking oil is obtained from university cafeteria (UMP, Gambang) and spent bleaching clay is collected from Felda Global Venture in Kuantan. Commercial CaO (99.99\% purity), chloroform (99.5\% purity) and methyl heptadecanoate (as an internal standard) of chromatographic grade (99.5\% purity) were obtained from Sigma-Aldrich (Switzerland), was used as an internal standard whereas methanol (99.5\% purity), petroleum ether $(90.0 \%$ purity) and hexane ( $\geq 99.0 \%$ purity) were purchased from Bendosen Laboratory Chemicals (Norway).

\subsection{Catalyst preparation}

De-oiled spent bleaching clay (25 g) was added into $100 \mathrm{~mL}$ distilled water and was placed into $250 \mathrm{~mL}$ flask held in an ultrasonic water bath for 3 hours. The Ca-functionalized
D-SBC sample was prepared at 40 wt. $\% \mathrm{CaO}$ (from D-SBC weight) where using the commercial $\mathrm{CaO}$. It then was dried in an oven at 120 ${ }^{\circ} \mathrm{C}$ for $16 \mathrm{~h}$. Upon drying, the D-SBC particle was calcined at $500{ }^{\circ} \mathrm{C}$ for 4 hour. Hammett indicators were used to test the basic strength of the catalyst. About $25 \mathrm{mg}$ of sample were shaken with $1 \mathrm{~cm}^{3}$ of a solution of Hammett indicator diluted in methanol and left to equilibrate for $2 \mathrm{~h}$.

\subsection{Transeterification reaction}

Waste cooking oil that was obtained from local cafeteria contained comparatively high free fatty acid. Esterification is done first in order to reduce the high free fatty acid in the waste cooking oil. The transesterification of WCO was performed in a $50 \mathrm{~mL}$ 2-neck round bottom flask equipped with a reflux condenser and magnetic stirrer. The transesterification reaction between WCO and methanol was carried out in the liquid phase under atmospheric pressure, at $65^{\circ} \mathrm{C}$ for $1 \mathrm{~h}$ with continuous stirring. The effect of the molar ratio of methanol to oil (6:1 - 24:1 wt.\%), catalyst amount (3-10 wt.\%) and reaction duration $(2-10 \mathrm{~h})$ on the reaction were investigated. After the transesterification, the reaction mixture was allowed to cool to room temperature. ME was isolated by centrifugation from the layers (ME, glycerol and catalyst), and then the excessive amount of methanol and water was evaporated before the chromatographic analysis. The reaction were carried out three times in order to reflect the precision and errors of the results.

\subsection{Biodiesel Analysis}

The European regulation procedure EN 14103 was used to determine the concentration of ME. In this study, GC-FID (Agilent Technologies, 7890A GC-System) with capillary column DB-wax (length $60 \times$ internal diameter $0.25 \mathrm{~mm} \times$ film thickness $0.25 \mu \mathrm{m})$ using methyl heptadecanoate as an internal standard. The carrier gas is helium with a linear velocity of $40 \mathrm{cms}^{-1}$. The oven temperature was programmed at $190{ }^{\circ} \mathrm{C}$, held for $2 \mathrm{~min}$, then ramped at $10^{\circ} \mathrm{C}$ per min until it reached 230 ${ }^{\circ} \mathrm{C}$, and with a final hold time of $8 \mathrm{~min}$. The sample volume of $0.6 \mu \mathrm{L}$ was injected into GCFID. The peaks of ME were identified by comparing them with their respective ME standards. Methyl esters peaks were identified by comparing with standards and to quantify the conversion, the following Equation (1) is used. 
ME content $=\frac{A_{\text {Total }}-A_{I S T D}}{A_{I S T D}} \times \frac{C_{I S T D} \times V_{I S T D}}{M_{\text {Sample }}} \times 100 \%$

Where: $A_{\text {total }}=$ Total area of methyl ester peak from C14:0 to C18:3; $A_{\text {ISTD }}=$ Area of internal standard; $C_{I S T D}=$ Concentration of internal standard in $\mathrm{mg} / \mathrm{mL} ; V_{I S T D}=$ Volume of internal standard in $\mathrm{mL}$; and $M_{\text {sample }}=$ Mass of sample in $\mathrm{mg}$.

\section{Results and Discussion}

\subsection{Catalyst characterization}

The FT-IR spectra of D-SBC, $\mathrm{CaO}$, and the catalyst are displayed in Figure 1. For the peak at $1050 \mathrm{~cm}^{-1}$, it is due to siloxane bonds ( $\mathrm{Si}-\mathrm{O}-\mathrm{Si})$. Vibration of $\mathrm{M}^{+-} \mathrm{O}$ bond is shown at peaks $486-779 \mathrm{~cm}^{-1}$. In addition, FT-IR also displays a broad band at 1637, 3430 and a shoulder at $3250 \mathrm{~cm}^{-1}$, due to the bending and stretching of bridging - $\mathrm{OH}$. Peak was not found between 2800 and $3000 \mathrm{~cm}^{-1}$ which indicated that there is no organic compound in the silica after the treatment [30]. The catalyst shows characteristics of strong base during Hammett indicators test which basic strength lies between $15<\mathrm{H}_{-}<18.4$. The field emission scanning electron micrograph of the catalyst is presented in Figure 2 (a) together with Energy Dispersive X-ray (EDX) depicted in Figure 2 (b). It shows nearly to a spherical shape. From the BET result shown in Table $1, \mathrm{CaO}$ supported deoiled SBC shown as a mesoporous solid and the isotherm for this sample can be classified into type III of the IUPAC classification. Surface area of the catalyst slightly decreases due to $\mathrm{CaO}$ has filled the pores on the D-SBC surface.

\subsection{Optimal process conditions}

The conversion of biodiesel from triglycerides is depicted in Figure 3. Under optimize condition of 7 wt.\% catalyst loading, $12: 1$ methanol to oil molar ratio, at methanol reflux-
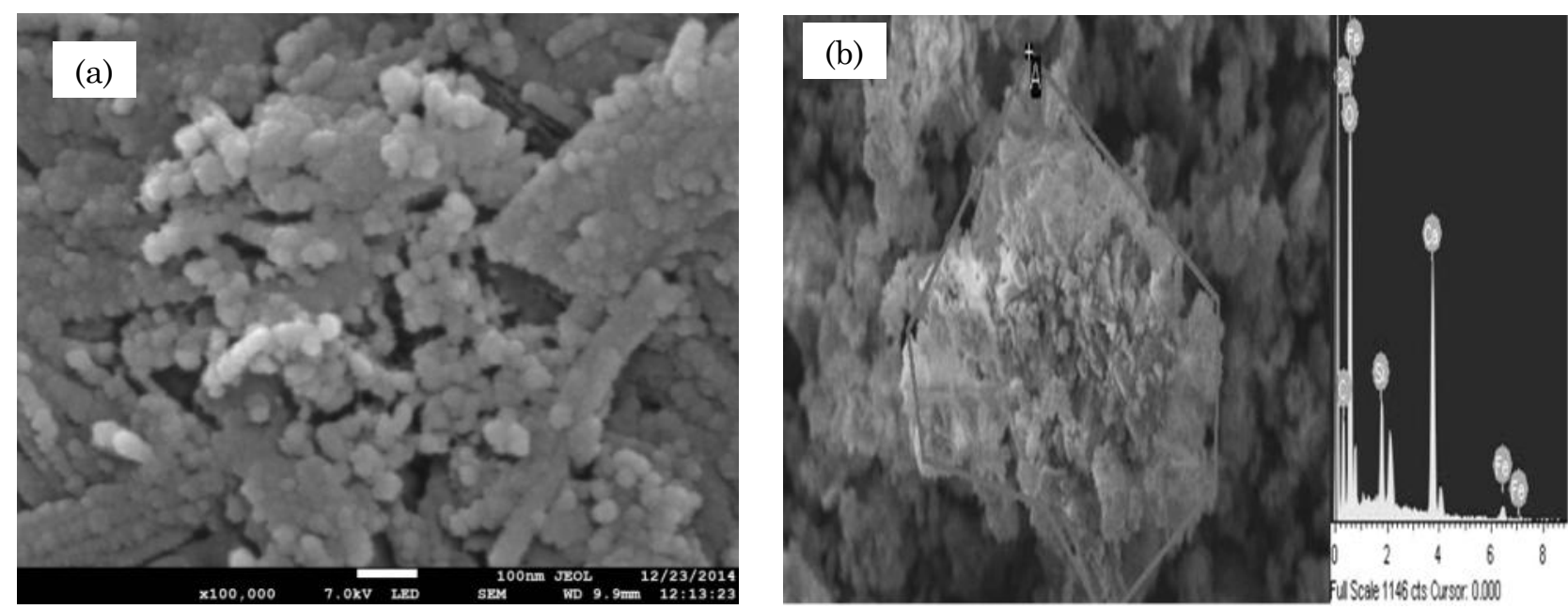

Figure 2. FESEM and EDX characterizations. (a). FESEM image of $40 \% \mathrm{CaO}$ on D-SBC; (b). EDX of the catalyst

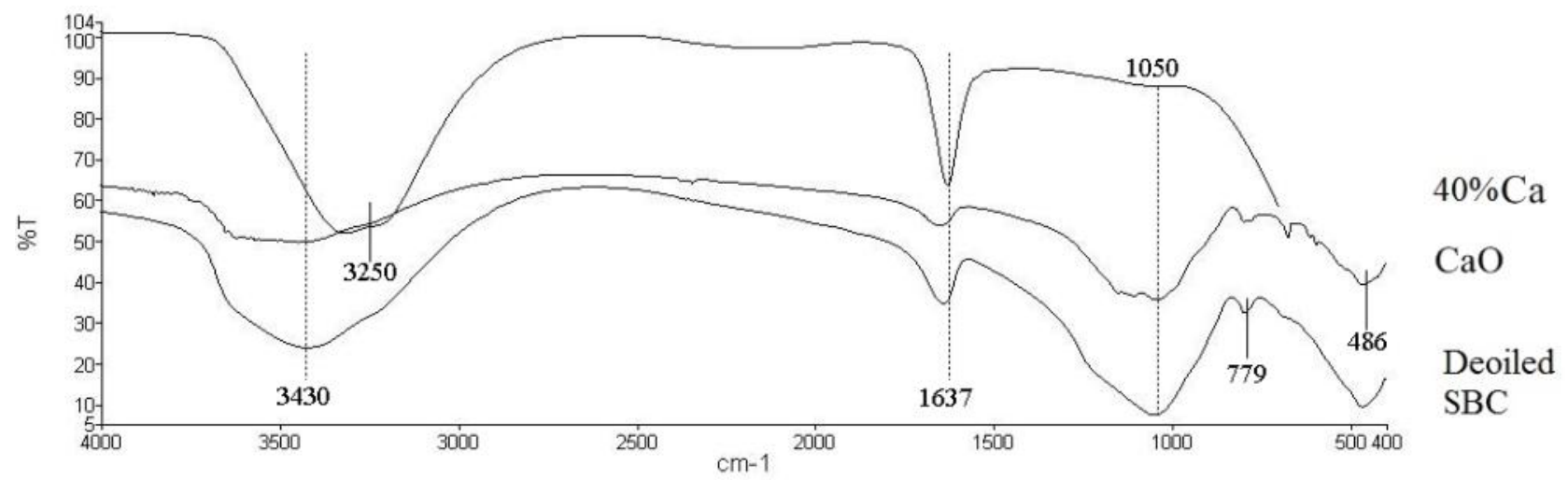

Figure 1. FTIR spectra of the catalysts 
ing temperature about $65 \pm 2{ }^{\circ} \mathrm{C}$ and $5 \mathrm{~h}$ reaction duration, conversion of $84.7 \%$ methyl ester is produced. Hence this catalyst shows its efficiency towards transesterification reaction. Based on Figure 3(a), catalyst amount shows that $7 \%$ (based on waste cooking oil weight) is optimum for this reaction. The amount of catalyst was varied from 3-10 wt.\%. The ME content reaches an optimal value when the catalyst amount reaches $7 \%$. This is because the contact opportunity of the catalyst and the reactant, directly affect the reaction speed and the content. Instead, increasing the amount of catalyst did not affect the content profoundly. This is probably because of the demand of higher power consumption for an adequate stirring speed and the solution becoming more viscous or may because of the surface vacancies of support material were filled with metals of

Table 1. BET result of the catalysts

\begin{tabular}{lccc}
\hline \multicolumn{1}{c}{ Sample } & $\begin{array}{c}\text { Surface } \\
\text { area }\left(\mathrm{m}^{2} / \mathrm{g}\right)\end{array}$ & $\begin{array}{c}\text { Pore } \\
\text { volume } \\
\left(\mathrm{cm}^{3} / \mathrm{g}\right)\end{array}$ & $\begin{array}{c}\text { Pore size } \\
(\AA)\end{array}$ \\
\hline $\begin{array}{l}\text { Deoiled-SBC } \\
\text { CaO with }\end{array}$ & 38.0212 & 0.243180 & 85.2033 \\
support & 36.9721 & 0.222066 & 233.6231 \\
\hline
\end{tabular}
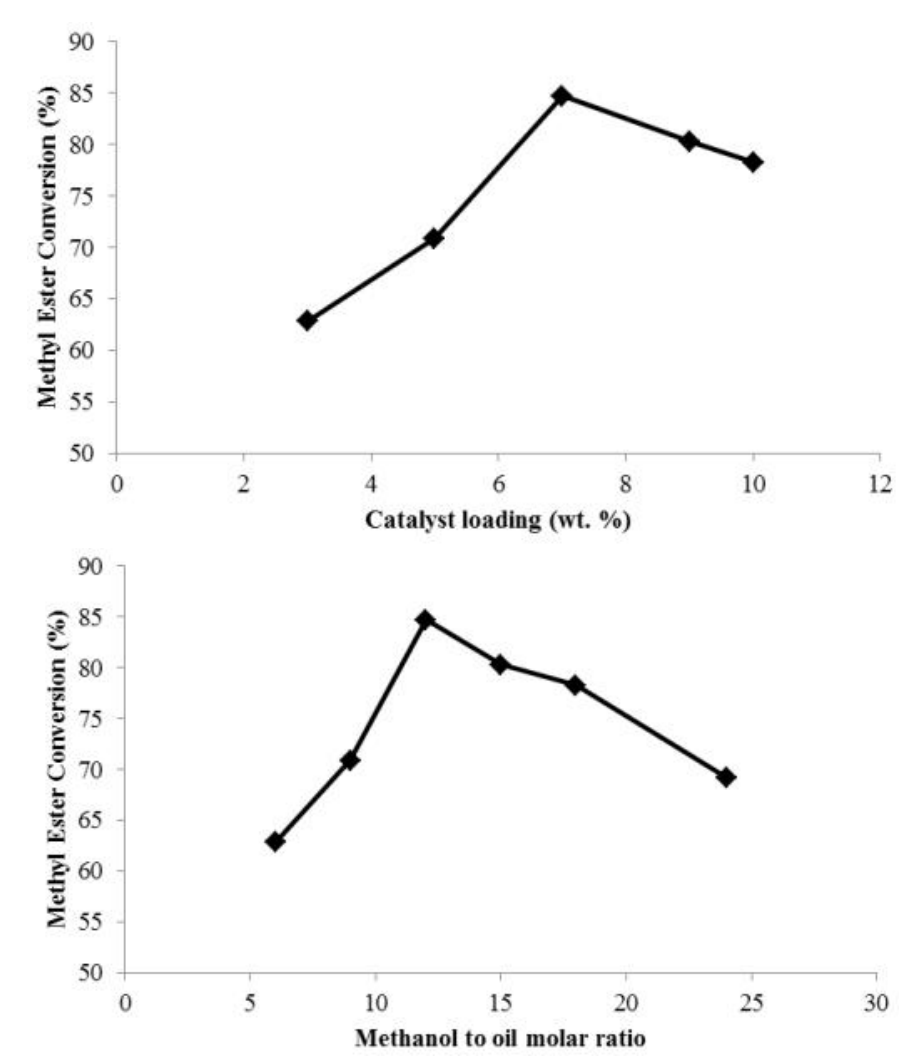

Figure 3. Effect of (a) catalyst loading, (b) reaction time, (c) methanol to oil molar ratio towards transesterification reaction (d) catalyst reusability under temperature $65 \pm 2{ }^{\circ} \mathrm{C}$ catalyst.

The catalyst is labeled as stronger than the indicator if exhibits a colour change and catalyst is said to be weaker than the indicator if not change the colour. This catalyst could change the colour of both phenolphthalein $\left(\mathrm{H}_{-}=8.2\right)$ from colurless to pink and of 2,4-dinitroaniline $\left(\mathrm{H}_{-}=15\right)$ from yellow to mauve but the colour of 4-nitroaniline $\left(\mathrm{H}_{-}=18.4\right)$ is failed to change. As depicted in Figure $3(\mathrm{~b})$, reaction duration is varied from 2-10 $\mathrm{h}$. The optimum duration for this reaction is shown to be $5 \mathrm{~h}$. Moreover, it is interesting to note that for longer reaction duration the ME content decreases, possibility due to the reverse reaction, since transesterification, is a reverse reaction resulting in a loss of esters as well as causing more fatty acid to form soap. Methanol to oil molar ratio is carried out in range 6:1 - 24:1. Methyl ester conversion dropped after 12:1 because of too much methanol will disturb the transesterification reaction thus causing in dropping the biodiesel production. As we can see from Figure 3 (c), variation of methanol to oil molar ratio, $12: 1$ gives the highest ME conversion. Unfortunately the excess of methanol could be increasing the recycling cost of production; nevertheless the methanol is usually recovered and reused in the industrial process after purification. Therefore, the
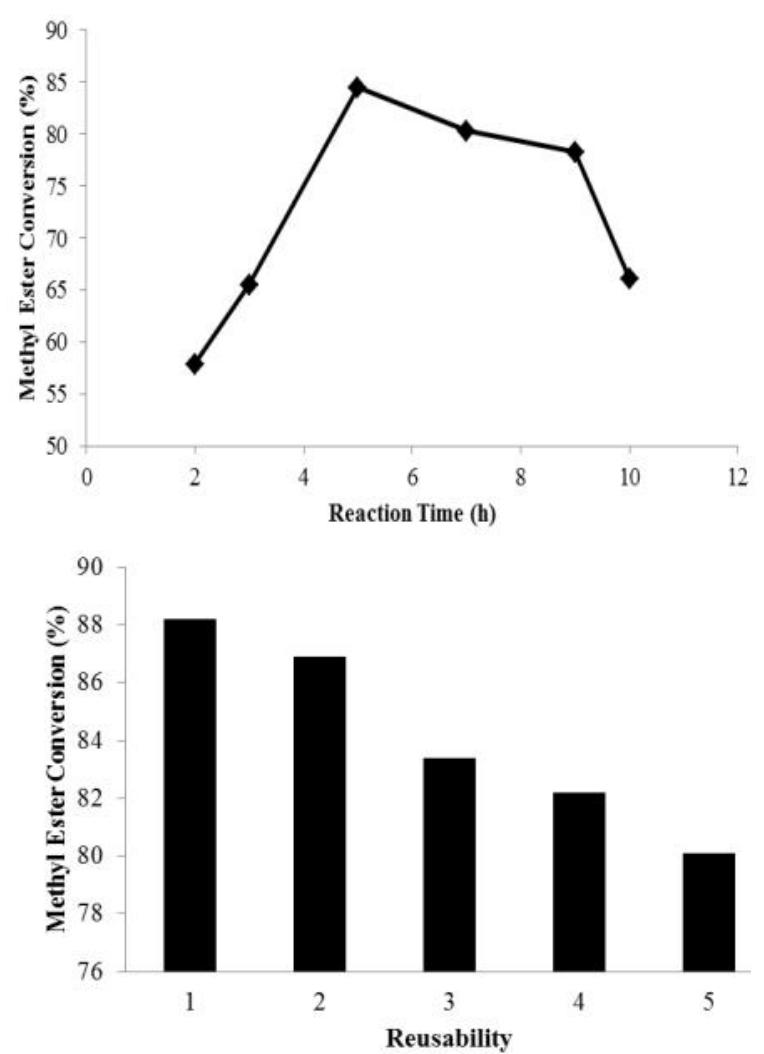
choice of an optimal molar ratio has to take the increase in process expense into consideration.

Reusability is one of the factors in the economical application of heterogeneous base catalyst. The catalyst was reused without any further activation. The results provided in Figure $3(d)$ show that the catalyst can be used more than once by keeping the activity until five cycles with considerably high ME content, while this result is inline with other researchers [17]. After the transesterification reaction was completed, the catalyst was decanted with simple washing using methanol then $\mathrm{n}$-hexane, and can be directly reused for the transesterification reaction. A ME content between 83-84\% could be obtained even after the third cycle. The ME content was further reduced to $80-82 \%$ when the catalyst was reused for four to five cycles, which might be due to the leaching from the catalyst, thus it will reduce the ME content during the next run of the reaction due to the reduction in the number of active sites in the catalyst.

For the leachability study, the catalyst was stirred with methanol for $1 \mathrm{~h}$ (without feedstock). Then the reacted catalyst and the treated methanol was separated. The methanol-reacted solid catalysts were subjected to transesterification under the optimal conditions. Similarly, the treated methanol was also subjected to transesterification but without any catalyst. A considerable $\mathrm{ME}$ content were achieved under methanol-reacted solid catalyst (75-80\%) whereas under the treated methanol (without any catalyst), a very low ME content (35-40\%) was observed. The observation proves that there is no complete leaching of the alkali metals into methanol during reaction.

\section{Conclusions}

The catalyst which derived from spent bleaching clay and commercial $\mathrm{CaO}$ found to give a high performance towards waste cooking oil via transesterification reaction into methyl ester. The FT-IR and XRF show that the impregnation of $\mathrm{CaO}$ onto deoiled spent bleaching clay as a support is a success. When the reaction was carried out at reflux of methanol, with a molar ratio of methanol to waste cooking oil of $12: 1$, TG conversion catalysed by $7 \%$ catalyst (based on the waste cooking oil weight) reached $84.7 \%$ in $5 \mathrm{~h}$. This catalyst can be used up to 5 cycles and has some leaching effect. The ME met several key specifications of European biodiesel standard (EN) 14214. Therefore, this catalyst has the potential to be used in the transesterification of waste cooking oil in producing biodiesel due to its high activity.

\section{Acknowledgment}

The authors thank Universiti Malaysia Pahang and the Ministry of Higher Education for the grants and financial support for Grant RDU150322 and RDU121402.

\section{References}

[1] Xie, W., Li, H. (2006). Alumina-Supported Potassium Iodide as A Heterogeneous Catalyst for Biodiesel Production from Soybean Oil. Journal of Molecular Catalysis A: Chemical. 255 (1-2):1-9.

[2] Mahdavi, V., Monajemi, A. (2014). Optimization of Operational Conditions for Biodiesel Production from Cottonseed $\mathrm{Oil}$ on $\mathrm{CaO}$ $\mathrm{MgO} / \mathrm{Al}_{2} \mathrm{O}_{3}$ Solid Base Catalysts. Journal of the Taiwan Institute of Chemical Engineers. 45: 2286-2292.

[3] Dias, J.M., Alvim-Ferraz-Maria, C.M., Almeida, M.F., Diaz, J.D.M., Polo, M.S., Rivera-Utrilla, J. (2012). Selection of Heterogeneous Catalyst for Biodiesel Production from Animal Fat. Fuel. 94: 418-425.

[4] Viriya-empikul, N., Krasae, P., Nualpaeng, W., Yoosuk, B., Faungnawakij, K. (2012). Biodiesel Production over Ca-Based Solid Catalysts Derived from Industrial Wastes. Fuel. 92: 239-244.

[5] Pugnet, V., Maury, S., Coupard, V., Dandeu, A., Qouineaud, A.A., Bonneau, J.L. (2010). Stability, Activity and Selectivity Study of A Zinc Aluminate Heterogeneous Catalyst for The Transesterification of Vegetable Oil in Batch Reactor. Applied Catalysis A: General. 374: 71-78.

[6] Alba-Rubio, A. C., Santamaria-Gonzalez, J., Merida-Robles, J.M., Moreno-Tost, R., Martin-Alonso, D., Jimenez-Lopez, A., MairelesTorres, P. (2010). Heterogeneous Transesterification Process by Using $\mathrm{CaO}$ Supported on Zinc Oxide as A Basic Catalysts. Catalysis Today. 149: 281-287.

[7] Albuquerque, M.C.G., Jimenez-Urbistondo, I., Santamaria-Gonzalez, J., Marida-Robles, J.M, Moreno-Tost, R., Rodriguez-Castellon, E., Jimenez-Lopez, A., Azevedo, D.C.S., Cavalcante Jr., C.L., Maireles-Torres, P. (2008). CaO Supported on Mesoporous Silicas as Basic Catalysts for Transesterification Reactions. Applied Catalysis A. General. 334: 35-43.

[8] Imaduddin, M., Yoeswono, Wijaya, K., Tahir, I. (2008). Ekstraksi Kalium dari Abu Tandan Kosong Sawit sebagai Katalis Pada Reaksi Transesterifikasi Minyak Sawit. Bulletin of Chemical Reaction Engineering \& Catalysis. 3 (1-3): 14-20.(in Indonesian)

(DOI: 10.9767/bcrec.3.1-3.7119.14-20) 
[9] Mat, R., Ling, O. S., Johari, A., Mohamed, M. (2011). In Situ Biodiesel Production from Residual Oil Recovered from Spent Bleaching Earth. Bulletin of Chemical Reaction Engineering \& Catalysis. 6 (1): 53-57.

[10] Correia, L.M., Saboya, R.M.A., Campelo, N.D.S., Cecilia, J.A., Rodriguez-Castellon, E., Cavalcante Jr., C.L., Vieira, R.S. (2014). Characterization of Calcium Oxide Catalysts From Natural Sources and Their Application in The Transesterification of Sunflower Oil. Bioresource Technology. 151: 207-213.

[11] Istadi, I., Pramudono, B., Suherman, S., Priyanto, S. (2010). Potential of $\mathrm{LiNO}_{3} / \mathrm{Al}_{2} \mathrm{O}_{3}$ Catalyst for Heterogeneous Transesterification of Palm Oil to Biodiesel. Bulletin of Chemical Reaction Engineering \& Catalysis. 5 (1): 51-56.

[12] Georgogianni, K.G., Katsoulidis, A.K., Pomonis, P.J., Manos, G., Kontominas, M.G. (2009). Transesterification of Rapeseed Oil For The Production of Biodiesel Using Homogeneous and Heterogeneous Catalysis. Fuel Processing Technology. 90: 1016-1022.

[13] Ho, W.W.S., Ng, H.K., Gan, S. (2012). Development and Characterization of Novel Heterogeneous Palm Oil Mill Boiler Ash-Based Catalysts for Biodiesel Production. Bioresource Technology. 125: 158-164.
[14] Madhuvilakku, R., Piraman, S. (2013). Biodiesel Synthesis by $\mathrm{TiO}_{2}-\mathrm{ZnO}$ Mixed Oxide Nanocatalyst Catalyzed Palm Oil Transesterification Process. Bioresource Technology. 150: 55-59.

[15] Samart, C., Chaiya, C., Reubroychareon, P. (2010). Biodiessel Production by Methanolysis of Soybean Oil Using Calcium Supported on Mesoporous Silica Catalyst. Energy Conversion and Management. 51: 1428-1431.

[16] Mat, R., Samsudi, R. A., Mohamed, M., Johari, A. (2012). Solid Catalysts and Their Application in biodiesel production. Bulletin of Chemical Reaction Engineering \& Catalysis. 7 (2): 142-149.

[17] Istadi, I., Mabruro, U., Kalimantini, B.A., Buchori, L., Anggoro, D.D. (2016). Reusability and Stability Tests of Calcium Oxide Based Catalyst $\left(\mathrm{K}_{2} \mathrm{O} / \mathrm{CaO}-\mathrm{ZnO}\right)$ for Transesterification of Soybean Oil to Biodiesel. Bulletin of Chemical Reaction Engineering \& Catalysis, 11(1): 34-39. (doi:10.9767/bcrec.11.1.413.3439)

Selected and Revised Papers from The International Conference on Fluids and Chemical Engineering (FluidsChE 2015) (http://fluidsche.ump.edu.my/index.php/en/) (Malaysia, 25-27 November 2015) after Peer-reviewed by Scientific Committee of FluidsChE 2015 and Reviewers of BCREC 